\title{
Conceptualizing Transdisciplinary Human Ecology
}

\author{
Sue L. T. McGregor ${ }^{1}$
}

McGregor Consulting Group, Nova Scotia, Canada

\section{Abstract}

Broadening theoretical and methodological underpinnings will help human ecology professionals remain effective in responding to complex crises facing humanity (e.g., climate change, environmental degradation, social inequality). Diversified theoretical offerings strengthen academic and professional work, because diversity drives innovation in practice. This paper explores transdisciplinary human ecology, a neologism proposed in the early 1990s by both ecological scientists and home economists. After describing home economics and ecological sciences' approaches to human ecology theory, the Nicolescuian transdisciplinary methodology, and transdisciplinary human ecology as conceived by home economics and ecological sciences, the paper shifts to an inaugural discussion of how human ecology theory can be augmented with Nicolescuian transdisciplinary axioms and transdisciplinary human ecology. This paper served as a seed catalyzing the uptake of transdisciplinary human ecology.

Keywords: ecological sciences, home economics, human ecology, transdisciplinarity, transdisciplinary human ecology

\section{Introduction}

Individuals and families face an array of deeply complex problems: "The severe challenges of climate change, resource depletion, environmental and social disintegration, and national and international inequality, are converging into a global crisis that confronts humanity as a whole" (Wahl, 2006, p. 288). Scholars in many disciplines are calling for transdisciplinarity, because they realize that knowledge from one discipline is insufficient. Trans means between, across, and beyond academic disciplines to include knowledge from the lifeworld (Nicolescu, 2002, 2014). Transdisciplinarity provides a solid foundation for investigating the complex interactions of human and socioecological systems that inform today's complex crises (Vaughan et al., 2019).

1 Corresponding author: sue.mcgregor@msvu.ca. 
Vaughan et al.'s (2019) comment links two long-standing lines of thinking: human ecology and transdisciplinarity. This paper focuses on transdisciplinary human ecology as understood within home economics (Brown, 1993) and ecological sciences (e.g., Dyball, 2010). Ecology is the science of the relationships between living organisms and their environments. Human ecology is the study of the relationships of a particular living organism-people — and their environments (Marten, 2001). "Ecologists study systems of interactions among differentiated organisms and between them and the nonliving components of their environment. ... Human ecology then, ought to mean simply and straightforwardly the study of ecosystems that involve humans" (Catton, 1994, p. 77, emphasis in original).

But human ecology is not a speciality contained within one discipline (Catton, 1994). Dyball (2010) concurred, explaining that human ecology "is adisciplinary, in that it is inclusive of the disciplines but is not bound by any" (p. 13) (see also Christensen, 2014). Biologists use it to study interactions between living organisms and their environments. Sociologists apply it to study human communities. Psychologists use it to explore interpersonal behavior and the adaptation of groups to resources available in their environments. Environmental design and engineering apply it to understand environmental psychology. Anthropologists, archaeologists, and geographers use it to study cultures and civilizations in environmental contexts. Political ecologists employ it to study the impact of colonialism, neoliberalism, and transnational corporations on resource management and environmental problems (Knapp, 2007; Touliatos \& Compton, 1988; Wolanski, 1990).

Of interest in this paper is that the ecological science discipline's approach to human ecology, as exemplified by Marten (2001), focuses on the interactions between social systems and ecosystems using complex adaptive systems theory. The home economics discipline is more narrowly focused on the family ecosystem as it interacts with levels of environments using general systems theory (Bubolz \& Sontag, 1993; Touliatos \& Compton, 1988). Indeed, home economics has long been concerned with human ecology; a fact recently recognized by leading ecological scientists in a paper titled "Ellen Swallow Richards: Mother of Human Ecology?" (Dyball \& Carlsson, 2017).

Dyball and Carlsson (2017) also acknowledged Richards as the founder of home economics during the late 1800s and early 1900s Lake Placid conferences in New York state. Richards's desire to call the new discipline human ecology was thwarted, because the name was already being used in the Dewey Library Decimal System with another definition (Joyce Beery Miles, personal communication, January 15, 2019). Richards is credited with being the first person to use the term human ecology in her 1907 book Sanitation in Daily Life, but attendees at the founding conferences (1899-1909) settled on home economics for the name of the new academic discipline and profession (Dyball \& Carlsson, 2017; Merchant, 2007). 
As a caveat, home economics is both a discipline (academic area of study) and mission-oriented profession (licensed, sanctioned provider of public service). Each depends on and thrives because of the other (McGregor, 2011a). Discipline is used herein, because professional practitioners depend on fellow academicians to develop theory. Also, American practitioners changed the name in 1994 to "family and consumer sciences" (FCS) (Vincenti, 1997). While respecting this preferred identity shift, the term home economics ${ }^{2}$ is used in this paper unless deemed too narrow in scope for the idea being developed.

Since the 1970s, the home economics discipline and profession have consistently drawn on human ecology theory (e.g., Bubolz \& Sontag, 1988, 1993; Touliatos \& Compton, 1988) with recent entreatment to embrace transdisciplinarity (McGregor, 2004, 2010, 2019a). The original thesis of this paper was that neither the home economics discipline nor profession has taken up transdisciplinary human ecology as recommended by Brown in 1993. In the course of developing this thesis, the author discovered that ecological scientists have been (and continue to be) drawn to and advocate for its usage (antithesis). This discovery shaped the argument herein.

After describing both home economics' (Brown, 1993) and ecological science's (Marten, 2001) approach to human ecology theory followed with Nicolescuian transdisciplinarity, the discussion turns to an overview of how both home economists and ecological scientists envisioned transdisciplinary human ecology. The paper ends with inaugural thoughts on how human ecology theory can be augmented with Nicolescuian transdisciplinary axioms and transdisciplinary human ecology (synthesis).

\section{Home economics' approach to human ecology theory}

A theory is a system of ideas intended to account for a phenomenon-Greek phainomenon, "a thing appearing, then seen or viewed." Theory is Greek theoria, "contemplation, speculation" (Harper, 2020). Theories help researchers explain, describe, predict, or control a phenomenon by arranging what is known about it "into a logical and understandable framework" (Touliatos \& Compton, 1988, p. 12). Any theoretical framework comprises three key building blocks: (a) assumptions (premises, tenets) about the phenomenon; (b) constructs and concepts with attendant definitions; and (c) propositions about how these concepts are related (McGregor, 2018b).

2 Ideas in this paper pertain to home economics (a term commonly used outside of the United States), FCS, human ecology, home sciences, home ecology, consumer sciences, family studies and other monikers for home economics around the world. 
In their scholarship focused on the well-being and quality of life of individuals and families in communities, home economists rely on several dominant theories including systems, conflict, exchange, symbolic interaction, family development, communication, and life course theory (Boss et al., 1993). The discipline also draws on consumer behavior, education, psychology, sociology, economic, political, and other theories (McGregor, 2009). Human ecology theory was introduced to home economics in the 1970s and early 1980s (see Bubolz et al., 1979; Bubolz, et al., 1980; Hook \& Paolucci, 1970). As noted, the discipline's founders considered buman ecology as its preferred name, but they were told they could not adopt it, because the biological sciences were already using it (Bubolz \& Sontag, 1993; Dyball \& Carlsson, 2017; Vincenti, 1997).

In their seminal work about human ecology theory, home economists Bubolz and Sontag (1993) identified a comprehensive list of assumptions and premises about the phenomenon of individuals and families (including households) in interaction with their environments (see pp. 425-426). Briefly, human ecology theory assumes that families are: (a) an ecosystem where the parts and the whole are interdependent: (b) a key democratic social institution that carries out functions for its members and the common good; and (c) a key player in the ecological health of the Earth and the world - families are part of the total life system of the planet and deeply intertwined with nonhuman life and environments. It further assumes that: (d) all of their decisions impact society, culture, and environments; and (e) humans (families) can control their decisions, which are not determined by environments. Instead, environments pose restrictions on and provide opportunities for human action (Bubolz \& Sontag, 1993).

Bubolz and Sontag (1993) then identified and defined an array of constructs and concepts shaping human ecology theory (pp. 429-437) with propositions (pp. 438439). Briefly, when using human ecology theory in their practice with individuals and families, home economics and FCS practitioners can assume that individuals, families, and households procure, use, and dispose of resources over time to meet basic needs and fulfill the basic functions of the family as a democratic unit. They do so by engaging in reciprocal relationships along four levels of environment: (a) human group, (b), human-built, (c), sociocultural, and (d) natural (Bubolz, 1990; Bubolz \& Sontag, 1988, 1993; Touliatos \& Compton, 1988) (see Figure 1).

Conceptually, these reciprocal relationships (i.e., humans with environments) require interaction, interdependence, adaptive behavior, and self-organization. People work with matter (material objects and artifacts), energy, resources, information, space, and time, augmented with technology. They engage in decision-making, choice-making, communication, and management. They exhibit a concern for values, norms, goals, attitudes, perceptions, and complexity as they strive to optimize the quality of both human life and environments (Bubolz \& Sontag, 1993). 


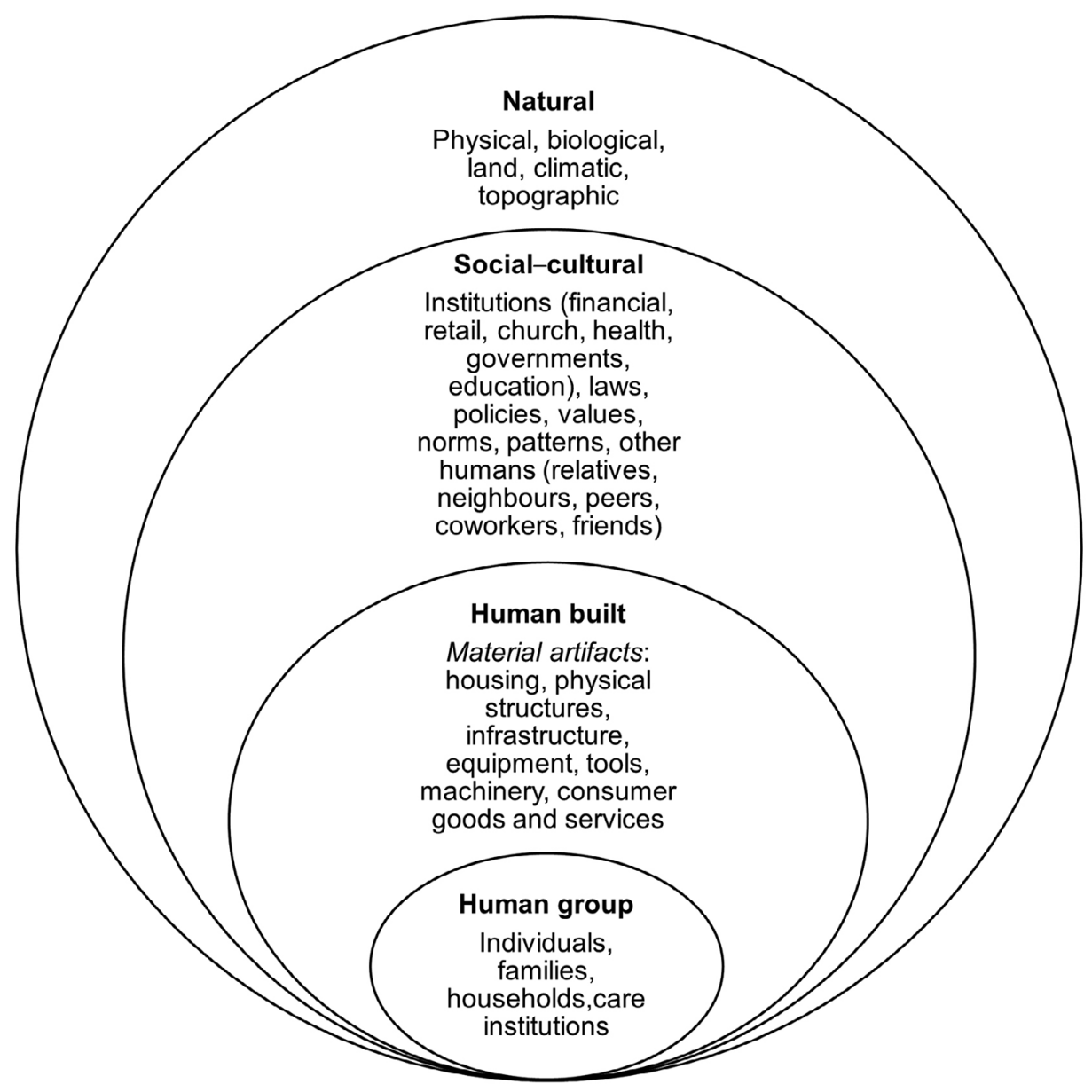

Figure 1. Levels of environment in home economics' human ecology theory.

Source: Author's summary of principles.

\section{Ecological scientists' approach to human ecology theory}

Home economics views human ecology theory as grounded in general systems theory concepts. They believe this theory provides a valuable perspective from which to focus on human-environmental interactions (Bubolz \& Sontag, 1993). Marten (2001) took a different approach. An ecological scientist, he turned to complex adaptive systems (CAS) theory to develop a theory of human ecology. As an aside, McGregor (2015b, 2019a) has also urged home economists to engage with CAS theory. 
Systems theory deals with input, throughput, output, and feedback while striving for equilibrium - picture a thermostat or paddling a canoe. On the other hand, CAS theory deals with complexity, chaos, and impermanent equilibrium-picture an undulating swarm of birds or a shifting herd of wildebeest. These complex systems are leaderless with no coordination; yet, things still happen. Patterns emerge, but no one was told to make a pattern. They are governed by chance and randomness, yet people trust that something will emerge (Mason, 2008). Other examples of CAS include the stock market, an anthill, and a family.

Using this well-established theory, Marten (2001) conceived human ecology theory through the lens of CAS principles and concepts. The most important of these are now introduced. A key concept is complexity, which refers to many intertwined, interdependent parts creating a complex whole that is difficult to untangle. CAS have the key property of emergence, which means gradually coming into existence. Emergence involves coadaptation, community assembly, and coevolution. CAS are resilient due to redundancy (i.e., the intentional duplication of system parts and functions to increase dependability). Of special importance, CAS are self-organizing - that is, they are adaptable (flexible) and can adjust to change without the need of external control or directions. They are also prone to interconnections and forming networks.

CAS are counterintuitive (do not act as expected) and unpredictable. They are chaotic, meaning order is emerging unpredictably. But they have stability domains (i.e., instances when they are stable) that accommodate tensions and switching in ecosystem states. They can experience distortion followed by a complex system cycle wherein they move from growth, equilibrium (stability), dissolution, and reorganization to a new stability domain. And they can create ecological niches whereby they respond to environmental conditions and create a suitable and sustainable role for themselves. Marten presented these and other CAS constructs as a "clear, understandable and coherent system of concepts for comprehending how ecosystems function and how human societies interact with ecosystems" (2001, p. xvi). Since then, other ecological scientists have acknowledged the merit of drawing on CAS theory to inform human ecology theory (Reyers et al., 2010).

\section{Nicolescuian transdisciplinary methodology}

Theories conceptualize a phenomenon. To learn more, scholars use research methodologies to gain knowledge of the phenomenon. Methodology (not the same as methods) is a "branch of logic that shows how abstract logical principles [axioms] are to be applied to the production of knowledge" (Harper, 2020). Home economics and FCS academics and practitioners basically draw on three methodologies: empirical, interpretive, and critical (Brown \& Paolucci, 1979). McGregor (2018a, 2018b) 
explained elsewhere the respective philosophical axioms for each methodology: (a) what counts as reality, being, and existing-ontology; (b) what counts as knowing and knowledge-epistemology; (c) logic and reasoning (habits of the mind); and (d) the role of values in research-axiology.

Transdisciplinarity is offered here as a fourth research methodology in its own right with its own take on the four axioms. Transdisciplinarity refers to creating knowledge using a combination of disciplinary knowledge and ways of knowing in sectors other than the university setting (Nicolescu, 2002, 2014). To clarify, interdisciplinary knowledge creation is limited to between or among disciplines with no concern for beyond the higher education academy (Nicolescu, 2014). For more than a century, home economics has been interdisciplinary (Vincenti, 2009). Ecological science is also interdisciplinary (Dyball, 2010; Reyers et al., 2010; Wolanski, 1990).

Daniels (1980), a British home economist, first called for a shift to transdisciplinarity in the profession, followed 13 years later with Brown's (1993) recommendation. Another decade lapsed before home economist McGregor (2004) took up the cause. How the discipline and profession view transdisciplinarity has changed over time (McGregor, 2010) with McGregor (2018a, 2019a) now using the Nicolescuian formulation rather than the Zurich approach (distinctions at McGregor, 2015a). Each would offer a different conceptualization of transdisciplinarity, with this paper opting for Nicolescu's (2002) approach. Ecological scientists are also advocating for a shift to transdisciplinarity with most not referencing any particular approach (e.g., Brown et al., 2010; Reyers et al., 2010; Steiner, 1993; Vaughan et al., 2019).

\section{Nicolescuian transdisciplinarity}

Drawing on complexity science (including CAS theory), chaos theory, and quantum physics (rather than classical, Newtonian sciences), Basarab Nicolescu (2002, 2014), a quantum theoretical physicist, formulated a transdisciplinary methodology (shortened in his explanations below to TD) with its own unique axioms (see Figure 2). McGregor (2018a) tendered a detailed discussion of these axioms, presented here in their most rudimentary format. Nicolescu's (2014) intent was to push back against disciplinary fragmentation and specializations, reductionism, dualism, positivism (the scientific method), capitalism, and corporate- and technoled globalization. The alienation of humans from science and technology has created the crises that Wahl (2006) lamented, crises that cannot be solved using just disciplinary or sectoral knowledge (Brown, 1993; Nicolescu, 2002). Uniting humans (subjective) and science (objective) will nullify dualism, unify knowledge, and augment understandings of complexity and the world (Nicolescu, 2014). 


\begin{tabular}{|c|}
\hline $\begin{array}{c}\text { ONTOLOGY } \\
\text { Reality, Being and } \\
\text { Existence }\end{array}$ \\
\hline $\begin{array}{l}\text { - Reality exists on } \\
\text { many levels } \\
\text { organized by (1) } \\
\text { internal to humans } \\
\text { (TD-Subject where } \\
\text { perspectives and } \\
\text { consciousness flow) } \\
\text { and (2) external to } \\
\text { humans (TD-Object } \\
\text { where information, } \\
\text { facts and objective } \\
\text { data flow). The } \\
\text { subject and object } \\
\text { are able to } \\
\text { temporarily come } \\
\text { together because } \\
\text { their interface is (3) } \\
\text { mediated by the } \\
\text { Hidden Third (a } \\
\text { unifying, spirit- } \\
\text { opening force at play } \\
\text { in the zone of non- } \\
\text { resistance). A new } \\
\text { trans-Reality is } \\
\text { formed for that } \\
\text { initiative. }\end{array}$ \\
\hline
\end{tabular}

\begin{tabular}{|l|}
\hline \multicolumn{1}{|c|}{$\begin{array}{c}\text { EPISTEMOLOGY } \\
\text { Knowing and } \\
\text { Knowledge }\end{array}$} \\
\hline $\begin{array}{l}\text {-TD knowledge is co- } \\
\text { created in the zone } \\
\text { of non-resistance to } \\
\text { others' ideas. This } \\
\text { knowledge is } \\
\text { emergent, cross } \\
\text { fertilized (many } \\
\text { sectors), complex } \\
\text { (can adapt and self- } \\
\text { organize) and } \\
\text { embodied (made } \\
\text { whole by and owned } \\
\text { by everyone } \\
\text { involved). TD } \\
\text { knowledge is said to } \\
\text { be alive, always in- } \\
\text { formation, and } \\
\text { perpetually changing } \\
\text { with the context. }\end{array}$ \\
\hline
\end{tabular}
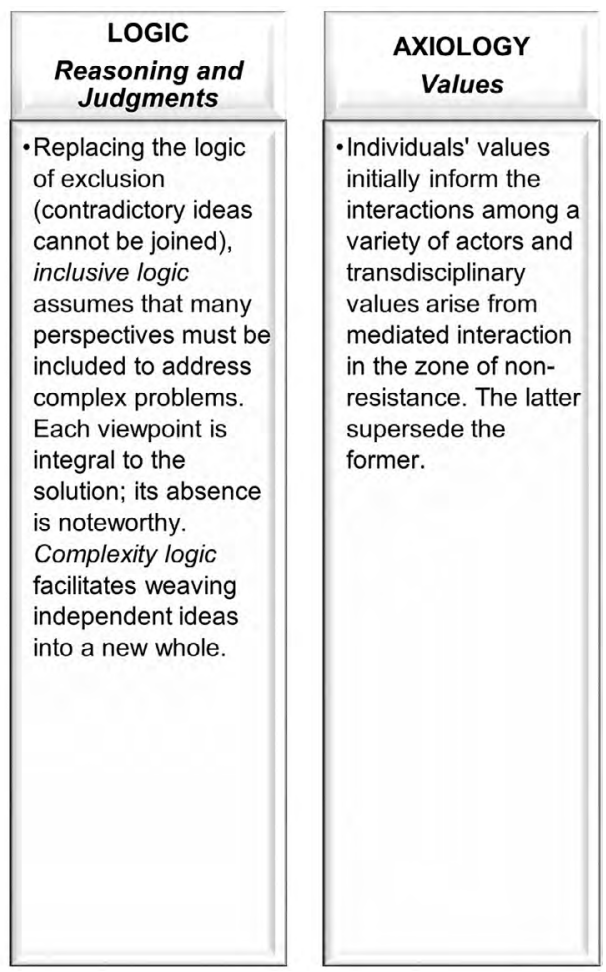

Figure 2. Nicolescuian transdisciplinary methodology axioms.

Source: Author's summary of axioms.

\section{Ontology}

Nicolescu believed that mixing what is inside people's minds (subjective, valueladen perceptions and consciousness) with what is outside their minds (external flow of objective, value-free information, facts, data, and statistics) is possible if the "included middle" interface is mediated with what he called the Hidden Third in conjunction with movement along multiple levels of Reality (ontology) (he capitalizes Reality-a convention used in this paper). The internal TD-Subject comprises individual (psychology and personal philosophy), social and cultural, political, and historical levels of Reality. The external TD-Object comprises other levels of Reality: economics and business, science and medicine, technology, environment and ecology, and planetary and cosmic (universe). Human movement between and among these levels of Reality is difficult because of their contradictory assumptions of the world (Nicolescu, 2002, 2014).

People need help to do this. To that end, Nicolescu conceptualized the mediating Hidden Third (like a third party during contentious negotiations), which entails culture, art, spirituality, religions, faith, and the Sacred (connections). These unifying modalities are a means to create a fertile space (called the zone of non-resistance), 
whereby antagonistic ideas from the TD-Subject and TD-Object can be smoothed over (ontology) so that new, integrated TD knowledge can emerge (epistemology). A new trans-Reality (beyond all Realities but existing at the time) arises that is multifaceted, pliable, in flux, and unique to the problem scenario being addressed (ontology) (Nicolescu, 2002, 2014).

\section{Epistemology}

Nicolescu's (2002, 2014) basic premise is that researchers and problem solvers need a way to reconcile natural resistance to contradictory ideas so they can integrate divergent worldviews. Knowledge can arise from this fusion of viewpoints when people willingly set aside their own views to make room for others. The resultant knowledge created in the fertile space where diverse minds interface (called the "fertile included middle") is emergent, complex, cross-fertilized, and embodied. It is cocreated and belongs to everyone involved (epistemology).

\section{Logic}

This conceptualization of ontology (Reality) is possible, because people can draw on both inclusive logic and the logic of complexity (Nicolescu, 2002)_Latin complexus, "plaited, interlaced strands" (Harper, 2020). Respectively, these logics (i.e., habits of the mind) (a) temporarily reconcile contradictions and antagonisms inherent in multiple perspectives and information (Realities), and (b) allow for different ways of knowing to be interwoven to form new TD knowledge (epistemology) (Nicolescu, 2002, 2014).

\section{Axiology}

Inherent in this process is a respect for both (a) personal value sets held when people enter the TD inquiry process, and (b) resultant TD values that emerge during and at the end (axiology) (e.g., respect, compromise, innovation). The new TD knowledge that is formed would not exist without these particular TD values (McGregor, 2018a; Nicolescu, 2014). Although Nicolescu (2006) did not formulate an axiology axiom, it is included here because home economics has long been concerned with values, values clarification (own values), values analysis (others' values), and values reasoning (Brown \& Paolucci, 1979). For those who are interested, McGregor (2011b) has made a case for a TD axiology.

To summarize, because transdisciplinary research is inquiry based (not discipline based), the focus is on investigating a complex issue and seeking information (object) and perspectives (subject) from academic disciplines and other sectors (e.g., civil society, industry, and government). Those involved integrate rather than exclude everyone into the inquiry process. All perspectives must be vetted to accommodate the complexity of the situation. Some points of view and/or facts may be integral to the final solution; their absence would be noteworthy and consequential. They are necessary for completeness (McGregor, 2018a; Montouri, 2013). 
To continue, TD researchers work across and with many sets of assumptions; that is, they use a meta-paradigmatic approach (Montouri, 2013). Meta is Greek, "across, with" (Harper, 2020). While accepting that each discipline and sector draws on its own set of assumptions (intra-paradigms), transdisciplinary researchers go further and tease out and challenge these assumptions (meta-paradigms). If unquestioned, they can place blinders on the inquiry process and preclude TD knowledge creation. Finally, reductionist, dualistic thinking is rejected in favor of complexity thinking (Montouri, 2013). The former reduces things to their bare essence, while the latter weaves things together to create a new essence (Nicolescu, 2016).

\section{Home economics' conceptualization of transdisciplinary human ecology}

Although it took ecological scientists until the end of the twentieth century to acquiesce to humanity's centrality to ecology (Reyers et al., 2010), Ellen Swallow Richards had proposed this connection at the end of the 1800s. Yet home economists did not embrace human ecology until the late 1970s (Brown, 1993; Dyball \& Carlsson, 2017; Vincenti, 1997). And unlike the growing cadre of ecological scientists who have conceptualized transdisciplinary human ecology (see next section), Brown (1993) is the only home economist who has engaged with the construct. She said that if the discipline intended to continue to align with human ecology, it should be a "broad, transdisciplinary human ecology" (Brown, 1993 , p. 413). She reasoned (at pp. 408-409) that, because home economics is concerned with human problems that do not fit within one discipline, any human ecology framework it adopted must be transdisciplinary.

Brown (1993) envisioned a transdisciplinary human ecology framework as overarching, embracing the global level, far beyond the human group. It would be normative in nature (i.e., asking should and ought questions privileging justice and rights) and focused on achieving valued ends that contribute to the potential of humankind, not just individuals and families. Transdisciplinary human ecology would also embrace all ways of knowing and be concerned with all "forms of relationships between humans and their environment" (p. 408). A transdisciplinary human ecology would assume that what constitutes a human problem is broadly defined, meaning it is large in scope while conceptually clear. It is a problem if it interferes with humans meeting their potential in society, which has implications for the human condition.

Brown (1993) proposed that transdisciplinary human ecology would provide a unified view of both the world and knowledge. It would appreciate "the contributions made by [all modes] of knowing" (p. 408). Unifying both the world and knowledge would require various disciplines and professions to work 
together to solve society's fundamental problems. This would necessitate using both a holistic view and reflection, otherwise home economists would not be able to synthesize knowledge. Transdisciplinary human ecology would also require specializations to rethink their orientation, so they can effectively bring their "special competence [to] political-moral activity [that is focused on solving issues] within human-environment relations" (p. 409).

\section{Ecological sciences' conceptualization of transdisciplinary human ecology}

Neither home economics nor FCS has engaged with Brown's (1993) vanguard idea of transdisciplinary human ecology as a new direction. However, her ecological science contemporaries saw the connection (e.g., Steiner, 1993; Wolanski, 1990), and their colleagues have been advocating for human ecology as transdisciplinary for the last 30 years (Christensen, 2014; Dyball, 2010; Reyers et al., 2010; WakefieldRann \& Fam, 2018).

To illustrate, Wolanski (1990) proposed that the human ecology discipline had moved through four stages_-mono, multi, inter and transdisciplinary (spanning 70 years) - entering the last stage in the early nineties. This was evident by the concern for a "transdisciplinary synthesis of the study of 'man and his culture as a dynamic part of ecosystems"” (p. 110). Wolanski felt it timely to conjoin human ecology with transdisciplinarity because of "the necessity of understanding man's essence in the light of the infinite complexity and temporariness of relations in the universe" (pp. 110-111). To clarify, man inclusively meant "organism, population, society" (p. 111).

Shortly thereafter, Steiner (1993) wrote of "human ecology as transdisciplinary" (p. 47) calling it "a trans-scientific endeavour" (p. 49), because human ecology goes beyond science to include philosophy and the lifeworld. Humans encounter their world on these "three levels of world reference which should be connected to each other" (p. 50). From a transdisciplinary perspective, "human ecology ... as an undertaking ... develops a capability of establishing a conceptual framework within which structured conversations about problems can take place and a new kind of consciousness can develop" (p. 51).

Steiner called this framework "general human ecology" (1993, p. 56). For him, the transdisciplinary perspective included (a) extended ecological (the transformation of existing systems) and (b) evolutionary (the emergence of new systems). The former is recursive and acknowledges that "interactions make possible an enduring existence of the elements [of a system] and the elements continue their very existence by further interactions" (p. 56). Evolutionary pertains to the emergence of new systems that 
arise from successive generations of recursive evolution and ongoing development. Steiner's (1993) approach to transdisciplinary human ecology thus depended on the transdisciplinary principles of recursive systems, self-organization, levels of reality, emergence, and evolution (in effect, CAS theory).

About 20 years later, Reyers et al. (2010) aligned transdisciplinarity with ecology. They explained that transdisciplinarity is best able to "tackle complexity and the fragmentation of knowledge, work with local contexts and uncertainty, and promote close collaboration and communication during all phases" (p. 503). This alignment happened because ecologists had finally accepted that ecosystem management and conservation is about people and their choices, not just about biology. For 50 years, ecologists had treated humans as external factors. No human ecological (reciprocal) relationship was appreciated, until it became self-evident that humans play a major role in what happens to natural environments and other biological species. Steiner (1993) agreed, claiming that "the ecological crisis is really a human crisis" (p. 57).

Dyball (2010) described human ecology as "necessarily transdisciplinary" (p. 274) because of its attributes. Human ecology "is about the interrelationships between humans, their cultures and their ecosystems" (p. 273). To that end, it uses a holistic approach, is concerned with the ethical dimensions of issues (especially for future generations), and is normative (asking should and ought questions). It also envisions a humane and sustainable future evidenced through a motivation of care and concern for a worthwhile world. These attributes make human ecology transdisciplinary whether intended or not (Dyball, 2010).

Christensen (2014) believed that "human ecology is inherently philosophical" (p. 47). He affirmed that "human ecology seeks knowledge useful for transforming human-environment interactions in the direction of sustainable living" (p. 44). Seeking such knowledge requires "reflectiveness, social and political engagement, and inner composure" (p. 44). He concluded that "human ecology [is] the distinctively philosophical appropriation of the results of whatever disciplines, techniques, and ... everyday knowledge are needed for ... generating a creative, practical response to the most serious crises human beings have ever confronted" (p. 47). With this description, he thus intimated that human ecology is transdisciplinary.

Very recently, Wakefield-Rann and Fam (2018) enticed their ecological science peers to view "indoor ecosystems as a complex issue [that requires the application of] the principles of transdisciplinarity" (p. 6). Transdisciplinary human ecology would involve "critical reflection in relation to one's own and others' perspectives, values, data, and methodological approaches [and conventions] that inevitably creates challenges" (p. 6). By engaging in collaborative research that transgresses disciplinary boundaries and uses multiple sources of knowledge from stakeholders and disciplines, ecological scholars could generate normative research yielding broad societal outcomes that would be communicated using language accessible across fields of inquiry and outside the academy. 


\section{Conceptualizing transdisciplinary human ecology}

This final section draws on home economics' and ecological scientists' conceptualizations of transdisciplinary human ecology to formulate an inaugural discussion of (a) transdisciplinary methodology and human ecology theory compatibility, (b) suggested realignments of particular human ecology theoretical concepts with transdisciplinary methodology, and (c) augmentations to human ecology theory so it can accommodate both (i) Nicolescuian transdisciplinarity axioms and (ii) home economists' and ecologists' views on transdisciplinary human ecology. (d) Implications for research are briefly acknowledged.

\section{Transdisciplinary methodology and human ecology theory compatibility}

Brown (1993) felt that "a transdisciplinary framework of human ecology ... provides a perspective which home economists could use but it does not provide the answers as to how this perspective can be used in home economics. That home economists must do themselves" (p. 409, emphases in the original). In that spirit, human ecology professionals and researchers can rest assured that the two are deeply complementary. To explain, any research methodology (i.e., assumptions about reality, knowledge, logic, and values) must align with the chosen theory (i.e., assumptions about the phenomenon under study) (McGregor, 2018b). Fortuitously, the transdisciplinary research methodology is concerned with inclusiveness, integration, complexity, and levels of Reality. This means it aligns closely with human ecology theory, which assumes people are in complex, reciprocal relationships within levels of environments.

Individuals, the family unit, and households are encountering incredibly complex problems that single disciplines cannot address (Brown, 1993). Fortunately, the transdisciplinary methodology is concerned with creating complex knowledge to address complex problems, which human ecology theory assumes people contribute to daily with their resource management choices (Bubolz \& Sontag, 1993; Reyers et al., 2010; Steiner, 1993). Transdisciplinary human ecology is an even more promising way to address complex societal concerns.

On another encouraging note, transdisciplinarity takes different forms in different practices and contexts: "There is no single such practice" (Riedy, 2016, p. 93). Because there are many ways to do transdisciplinarity, home economics, FCS, and ecological science theorists can choose to bring transdisciplinarity to human ecology. Already interdisciplinarians and adherents of human ecology theory, home economics, FCS, and ecology researchers should feel comfortable embracing transdisciplinary human ecology. 
Home economists and FCS theorists and practitioners already value humans, ecologies, levels, integration, holism, and cross fertilization (Bubolz \& Sontag, 1988; McGregor, 2019b), which are all key components of transdisciplinary work. Similarly, human ecology theory and the transdisciplinary methodology share key concepts: interaction, adaptation, self-organization, interdependence, complexity, reciprocity, and a concern for environments. In short, transdisciplinary methodology (axioms) and human ecology theory (assumptions) are compatible.

\section{Suggested conceptual realignments}

Several human ecology theoretical concepts can be realigned with aspects of transdisciplinary methodology. First, both approaches have a concern for space, time, cyber technology, energy, and material artifacts. Nicolescu $(1998,2002,2014)$ added the notion of cyber-space-time (CST) (ontology), which is a connecting principle bridging mind and matter to make levels of perception more evident as people cross Realities. CST is "the transcultural, transnational and transpolitical ... space of human choice" (Nicolescu, 2002, p. 82); that is, people choose to work with disparate minds to problem solve.

Inclusive logic (not leaving anything out) is at work in CST, which is simultaneously artificial (e.g., information technology, Internet, virtual reality) and real, just with different degrees of materiality (more than dualistic, either real or virtual) (Nicolescu, 2002). "'Cyber'space is a ritually created space of liminality with transformative properties" (Barbatsis et al., 1999). Liminal space is barely perceptible, neither here nor there. When people enter it, they stand on a threshold, where something can cease to exist or can come into existence-transform (Turner, 1974). Respectively, people can let go of old ways of seeing things and create new knowledge in CST.

On a second front, transdisciplinarity's respect for religion, faith, spirituality, and the Sacred are not an explicit part of human ecology theory now except for the inclusion of church and culture in the social-cultural environment level (Bubolz $\&$ Sontag, 1993) (see Figure 1). It makes conceptual sense to add these ontological elements of transdisciplinarity's Hidden Third to human ecology theory. (a) Church represents institutionalized religion as a political and social force. (b) Religions are historical and cultural systems and rituals built around a deity. (c) Faith is an individual's belief in the deity, Church, or religious system. (d) Spirituality is the essential essence of humanity - an inner force. (e) The Sacred represents an absolute respect for others and attendant life-affecting connections (e.g., humans and nature) (McGregor, 2018a; Nicolescu, 2002, 2014, 2016). Along with culture and art, these elements are considered "spirit-opening modalities" that relax people's minds to receive others' ideas (Eric Reynolds, personal communication, August 15, 2018). 
Third, human ecology theory concerns the phenomenon of individuals and families in relation with environments (Bubolz \& Sontag, 1993). If the ecological crisis is a human crisis (Reyers et al., 2010; Steiner, 1993), the human group at the center of human ecology theory would have to be reconceptualized. This could include adding subjective perceptions, perspectives, and consciousness as well as human psychology, and philosophy of life (ontology) (Nicolescu, 2014). Human ecology is, by its nature, philosophical (Christensen, 2014). The human group would also have to include ethics and morality and have a normative dimension (Brown, 1993; Dyball, 2010).

\section{Augmented human ecology theoretical assumptions}

If the home economics and ecological disciplines heed the call to move forward with transdisciplinary human ecology, they will have to augment some of human ecology theory's assumptions (Bubolz \& Sontag, 1993; Marten, 2001) with transdisciplinary philosophical axioms (Nicolescu, 2002, 2014). The following augmentations are offered for consideration, organized by the four transdisciplinarity axioms. The preponderance of ontological ideas may align with Christensen's (2014) (ecological scientist) assertion that human ecology has a unique ontology, enriched here with transdisciplinarity ontology (i.e., multiple levels of Reality and the Hidden Third):

\section{Ontology}

- assuming humans are in relation with environments would require another, outermost, level of environment: the cosmos, universe, and lifeworld (see Figure 1);

- resources available for meeting basic needs and fulfilling the role of a democratic social institution would expand to include the CST construct;

- per the above, it is assumed that as they create their Reality, they will self-organize and move through complex system cycles;

- the inclusion of church and culture in the social-cultural level of environment would expand to include spirituality, religion, faith, and the Sacred;

- human consciousness would come into play during resource management and be affected by interfacing with others;

- although human ecology theory assumes humans can control their decisions and choices, this process would now be understood in the context of many other actors instead of just the home or household;

- as humans engage with four levels of environments, they would do so along multiple levels of Reality (internal subjective and external objective);

- the reciprocal relationship between humans and levels of environments would require mediation (the Hidden Third) if people intended to move through levels of Reality at the same time; 


\section{Epistemology}

- because family knowing and family knowledge are key to transdisciplinary knowledge creation, how families come to know things and what counts as family knowledge must be conceptualized and studied. This knowledge would be complex (more than complicated), emergent, and embodied;

- as they interact to create new knowledge, they would be construed as counterintuitive and unpredictable yet able to deal with chaos, which is order emerging unpredictably;

- individual and family ecosystem resource management would be construed as complex, emergent, and evolving rather than just complicated and ongoing;

- individuals and families would be viewed as resourceful ecological niches;

\section{Logic}

- the above mediation would involve considering inclusive logic and complexity logic (habits of the mind) as part of family reasoning and judgments and any articulation of insights and perspectives;

- assuming individuals and families are key players in the health of the world means their voices need to be heard in transdisciplinary work (inclusive);

- people would come to expect patterns to emerge, which will inform their logic and reasoning;

\section{Axiology}

- values are part of human ecology theory (in the sociocultural environment). Transdisciplinary human ecology would have to expand to make room for the emergence of transdisciplinary values, which are not explicitly created by humans but arise from the mediated interface where incompatibility and complexity are addressed to mutual satisfaction.

\section{Research implications}

On the research front, the empirical, scientific, positivistic approach is still needed-just not privileged (Nicolescu, 2014). The interpretive and critical research methodologies align most closely with transdisciplinarity, a research methodology in its own right. Interpretive methodology focuses on the meanings people assign to their lived experiences, while critical methodology is concerned with the role of power in people's lives. Appropriate research methods (sampling, data collection, analysis, and reporting conventions) include phenomenology (assigning meaning to lived experiences), hermeneutic inquiry (interpreting communications to find meaning), and discourse analysis (revealing power). Narrative inquiry (people's stories), action research (personal research and activism combined), and participatory research (collective research and activism combined) are also relevant (McGregor, 
2018b). Home economics, FCS, and ecological science practitioners should also engage with challenging but necessary collaborative initiatives (McGregor, 2017; Vincenti, 2009; Wakefield-Rann \& Fam, 2018).

\section{Conclusion}

Home economics', FCS's, and ecological science's current theoretical understandings of human ecology would change if informed by Nicolescuian transdisciplinarity. Discourse, meanings, processes, and outcomes pursuant to the use of human ecology theory would change too. Taking inspiration from Riedy (2016), this paper served as a seed catalyzing the uptake of transdisciplinary human ecology. Diversifying theoretical and methodological offerings (i.e., embracing transdisciplinary human ecology) would strengthen disciplinary and professional work because "diversity ... drives innovation in practice" (Riedy, 2016, p. 105). Innovative next practice better ensures continued effectiveness in responding to complex crises.

With a synthesis of contributions from both home economics and ecological sciences, a conceptualization of transdisciplinary human ecology was offered. The ideas herein should stimulate future discussions about the diverse, overall conceptual framework of human ecology as it pertains to traditional and contemporary intellectual offerings. As a mix of long-standing historical traditions and current and complex thinking, this paper can serve as a stimulus piece for people from a range of disciplinary and theoretical dimensions to reflect and comment on conceptualizing transdisciplinary human ecology.

\section{References}

Barbatsis, G., Fegan, M., \& Hansen, K. (1999). The performance of cyberspace: An exploration into computer-mediated reality. Journal of Computer-Mediated Communication, 5(1). doi.org/10.1111/j.1083-6101.1999.tb00332.x

Boss, P., Doherty, W. J., LaRossa, R., Schumm, W. R., \& Steinmetz, S. K. (Eds.). (1993). Sourcebook of family theories and methods. Springer. doi.org/10.1007/978-0-387-85764-0

Brown, M. M. (1993). Philosophical studies of home economics in the United States: Basic ideas by which home economists understand themselves (Vol. 3). Michigan State University Press.

Brown, M. M., \& Paolucci, B. (1979). Home economics: A definition [augmented version]. American Association for Family and Consumer Sciences.

Brown, V. A., Harris, J. A., \& Russell, J. Y. (Eds.). (2010). Tackling wicked problems through the transdisciplinary imagination. Earthscan. doi.org/10.4324/9781849776530 
Bubolz, M. M. (1990, April 20-22). The family ecosystem: Macro and micro interdependence [Paper presentation]. Society for Human Ecology Conference, East Lansing, Michigan, United States.

Bubolz, M. M., Eicher, J., Evers, S. J., \& Sontag, M. S. (1980). A human ecological approach to quality of life: Conceptual framework and results of a preliminary study. Social Indicators Research, 7(1-4), 103-136. doi.org/10.1007/bf00305595

Bubolz, M. M., Eicher, J., \& Sontag, M. S. (1979). The human ecosystem: A model. Journal of Home Economics, 71(1), 28-31. hdl.handle.net/11299/162560

Bubolz, M. M., \& Sontag, S. (1988). Integration in home economics and human ecology. Journal of Consumer Studies \& Home Economics, 12(1), 1-14. doi.org/10.1111/j.14706431.1988.tb00462.x

Bubolz, M. M., \& Sontag, S. (1993). Human ecology theory. In P. Boss, W. J. Doherty, R. LaRossa, W. R. Schumm, \& S. K. Steinmetz (Eds.), Sourcebook of family theories and methods: A contextual approach (pp. 419-448). Plenum Press. doi.org/10.1007/978-0387-85764-0_17

Catton, W. R., Jr. (1994). Foundations of human ecology. Sociological Perspectives, 37(1), 75-96.

Christensen, C. B. (2014). Human ecology as philosophy. Human Ecology Review, 20(2), 31-49. doi.org/10.22459/her.20.02.2014.02

Daniels, C. E. J. (1980). The organizational structure of home economics: A consideration of terminology. Journal of Consumer Studies and Home Economics, 4(4), 323-339. doi.org/ 10.1111/j.1470-6431.1980.tb00385.x

Dyball, R. (2010). Human ecology and open transdisciplinary inquiry. In V. A. Brown, J. A. Harris, \& J. Y. Russell (Eds.), Tackling wicked problems through the transdisciplinary imagination (pp. 273-284). Earthscan. doi.org/10.4324/9781849776530

Dyball, R., \& Carlsson, L. (2017). Ellen Swallow Richards: Mother of human ecology? Human Ecology Review, 23(2), 17-28. doi.org/10.22459/her.23.02.2017.03

Harper, D. (2020). Online etymology dictionary. etymonline.com/

Hook, N., \& Paolucci, B. (1970). The family as an ecosystem. Journal of Home Economics, 62(5), 315-318.

Knapp, G. (2007). Human ecology. In P. Robbins (Ed.), Encyclopedia of environment and society (Vol. 3) (pp. 880-884). Sage.

Marten, G. (2001). Human ecology: Basic concepts for sustainable development. Earthscan. doi.org/10.4324/9781849776028

Mason, M. (Ed.). (2008). Complexity theory and the philosophy of education. Wiley-Blackwell.

McGregor, S. L. T. (2004). The nature of transdisciplinary research and practice. Kappa Omicron Nu Human Sciences Working Paper Series. kon.org/resources/the-nature-of-transdiscipliaryresearch-and-practice.html 
McGregor, S. L. T. (2009). Integral metatheory: Beyond specializations, theoretical pluralism and conventional metatheory. Family and Consumer Sciences Research Journal, 38(2), 142-157. doi.org/10.1111/j.1552-3934.2009.00014.x

McGregor, S. L. T. (2010). Historical notions of transdisciplinarity in home economics. Kappa Omicron Nu FORUM, 16(2). www.kon.org/archives/forum/16-2/mcgregor.html

McGregor, S. L. T. (2011a). Home economics in higher education: Pre-professional socialization. International Journal of Consumer Studies, 35(5), 560-568. doi.org/10.1111/ j.1470-6431.2011.01025.x

McGregor, S. L. T. (2011b). Transdisciplinary axiology: To be or not to be. Integral Leadership Review, 11(3). integralleadershipreview.com/3388-transdisciplinary-axiology-to-be-ornot-to-bel

McGregor, S. L. T. (2015a). The Nicolescuian and Zurich approaches to transdisciplinarity. Integral Leadership Review, 15(3). integralleadershipreview.com/13135-616-the-nicole scuian-and-zurich-approaches-to-transdisciplinarity/

McGregor, S. L. T. (2015b). Vanguard next practice for home economics: Complexity thinking, integral thinking, and the human condition. International Journal of Home Economics, 8(1), 64-77.

McGregor, S. L. T. (2017). Challenges to transdisciplinary collaboration: A conceptual literature review. Integral Leadership Review, 17(1). integralleadershipreview.com/15402challenges-of-transdisciplinary-collaboration-a-conceptual-literature-review/

McGregor, S. L. T. (2018a). Philosophical underpinnings of the transdisciplinary research methodology. Transdisciplinary Journal of Engineering \& Science, 9, 182-198. doi.org/ $10.22545 / 2018 / 00109$

McGregor, S. L. T. (2018b). Understanding and evaluating research: A critical guide. Sage. dx.doi.org/10.4135/9781071802656

McGregor, S. L. T. (2019a). Paradigms and normativity: What should FCS do in light of 21st century change? Journal of Family \& Consumer Sciences, 111(3), 10-25. doi.org/ 10.14307/jfcs 111.3 .10

McGregor, S. L. T. (2019b). Valuing the holistic approach. International Journal of Home Economics, 12(1), 55-62.

Merchant, C. (2007). American Environmental History. Columbia University Press.

Montouri, A. (2013). The complexity of transdisciplinary literature reviews. Complicity, 10(1-2), 45-55. doi.org/10.29173/cmplct20399

Nicolescu, B. (1998). Relativité et physique quantique [Relativity and quantum physics]. In M. Cazenave (Ed.), Dictionnaire de l'ignorance (pp.108-120). Albin Michel.

Nicolescu, B. (2002). Manifesto of transdisciplinarity (K-C. Voss, Trans.). SUNY Press. 
Nicolescu, B. (2006). Transdisciplinarity-Past, present and future. In B. Haverkort \& C. Reijntjes (Eds.), Moving worldviews: Reshaping sciences, policies and practices for endogenous sustainable development (Vol. 4) (pp. 142-163). ETC/Compas. bibalex.org/ Search4Dev/files/416884/362466.pdf

Nicolescu, B. (2014). From modernity to cosmodernity. SUNY Press.

Nicolescu, B. (2016). The hidden third (W. Garvin, Trans.). Quantum Prose.

Reyers, B., Roux, D. J., \& O’ Farrell, P. J. (2010). Can ecosystem services lead ecology on a transdisciplinary pathway? Environmental Conservation, 37(4), 501-511. doi.org/ $10.1017 /$ s0376892910000846

Richards, E. H. (1907). Sanitation in daily life. Whitcomb \& Burrows.

Riedy, C. (2016). Seeding a new transdisciplinary community of practice. In D. Fam, J. Palmer, C. Riedy, \& C. Mitchell (Eds.), Transdisciplinary research and practice for sustainability outcomes (pp. 93-106). Earthscan. doi.org/10.4324/9781315652184

Steiner, D. (1993). Human ecology as transdisciplinary science and science as part of human ecology. In M. Nauser \& D. Steiner (Eds.), Human ecology (pp. 47-76). Routledge. doi.org/10.4324/9780203414989

Touliatos, J., \& Compton, N. H. (1988). Research methods in human ecology/home economics. Iowa State University Press.

Turner, V. (1974). Liminal to liminoid, in play, flow, and ritual: An essay in comparative symbology. Rice University Studies, 60(3), 52-92.

Vaughan, J., Mallett, C. J., Davids, K., Potrac, P., \& Lópex-Felip, M. A. (2019). Developing creativity to enhance human potential in sport: A wicked transdisciplinary challenge. Frontiers in Psychology, 10, Article 2090. doi.org/10.3389/fpsyg.2019.02090

Vincenti, V. B. (1997). Home economics moves into the twenty-first century. In S. Stage \& V. Vincenti (Eds.), Rethinking home economics (pp. 301-320). Cornell University Press. doi.org/10.7591/9781501729942-017

Vincenti, V. B. (2009). Family and consumer sciences university faculty perceptions of interdisciplinary work. Family and Consumer Sciences Research Journal, 34(1), 81-104. doi.org/10.1177/1077727x05277742

Wahl, D. C. (2006). Design for human and planetary health: A transdisciplinary approach to sustainability. In C. A. Brebbia, M. E. Conti, \& E. Tiezzi (Eds.), Management of natural resources, sustainable development and ecological hazards (pp. 285-296). WIT Press. doi.org/ $10.2495 /$ rav060281

Wakefield-Rann, R., \& Fam, D. (2018). Initiating a transdisciplinary conversation to improve indoor ecologies. Human Ecology Review, 24(2), 3-22. doi.org/10.22459/ her.24.02.2018.01

Wolanski, N. (1990). Origin and methodology of human ecology. Journal of Human Ecology, 1(2), 109-119. doi.org/10.1080/09709274.1990.11907665 
This text is taken from Human Ecology Review, Volume 26, Number 1, 2020, published by ANU Press, The Australian National University, Canberra, Australia. doi.org/10.22459/HER.26.01.2020.11 